\title{
Performance of capillary barrier as a sustainable slope protection
}

\author{
Alfrendo Satyanaga ${ }^{1, *}$, Qian Zhai ${ }^{2}$, Harianto Rahardjo ${ }^{3}$, Gilson de F.N. Gitirana $\mathrm{Jr}^{4}$, Sung-Woo Moon ${ }^{5}$, and Jong Kim ${ }^{6}$ \\ ${ }^{1}$ Assistant Professor, Department of Civil and Environmental Engineering, Nazarbayev University, 53 Kabanbay Batyr Ave, 010000 , \\ Nur-Sultan, Kazakhstan \\ ${ }^{2}$ Associate Professor, Key Laboratory of Concrete and Prestressed Concrete Structures of Ministry of Education, Southeast University, \\ Nanjing 210096, China \\ ${ }^{3}$ Professor, School of Civil and Environmental Engineering, Nanyang Technological University, Block N1, Nanyang Ave., Singapore \\ 639798, Singapore \\ ${ }^{4}$ Associate Professor, School of Civil and Environmental Engineering, Universidade Federal de Goiás, Goiânia 74605-220, Brazil \\ ${ }_{5}^{5}$ Assistant Professor, Department of Civil and Environmental Engineering, Nazarbayev University, 53 Kabanbay Batyr Ave, 010000 , \\ Nur-Sultan, Kazakhstan
}

${ }^{6}$ Professor, Department of Civil and Environmental Engineering, Nazarbayev University, 53 Kabanbay Batyr Ave, 010000, Nur-Sultan, Kazakhstan

\begin{abstract}
Capillary barrier system (CBS) was developed as a slope protection method to prevent rainwater infiltration into the underlying soil based on the principle of unsaturated soil mechanics by harnessing the distinct difference in hydraulic properties of a fine-grained layer with those of a coarse-grained layer of soils. The CBS is commonly designed and constructed using gravel as coarse-grained material and fine sand as fine-grained material. However, due to scarcity of natural aggregates and in consideration of environmental sustainability, there is a need to utilize recycled materials in capillary barrier system. In this project, coarse and fine recycled concrete were used as the coarse- and fine-grained materials, respectively. The appearance of CBS was enhanced with an additional layer of approved soil mixture (ASM) to incorporate vegetation as green cover. CBS as a sustainable slope cover has been constructed for slope protection surrounding basement carpark in the new public housing development at Matilda, Singapore. The design, construction and monitoring system for the CBS are presented and discussed in this paper. The field measurement data provide verification of the performance of the CBS. Both field measurement and numerical analyses demonstrated that CBS performed well as designed.
\end{abstract}

\section{Introduction}

Capillary barrier system (CBS) is a cover system commonly consisting of a relatively fine soil layer placed over a relative coarse soil layer ([1], [2]). The schematic diagram of the capillary barrier system is illustrated in Figure 1.

CBS has been studied as a soil cover for landfill and mines wastes to reduce water infiltration ([3], [4]). Physical models have been constructed by different researchers ([5], [6]) to investigate the effectiveness of CBS in preventing water infiltration. Rahardjo et al. (2012) [7] carried out parametric studies on three capillary barrier models and suggested to use a material combination with a $\psi_{\mathrm{w}}$-ratio, which is the ratio of the water-entry values of the fine- and coarse- grained layer, greater than 10. Rahardjo et al. (2012 [8], 2013 [9]) also presented that additional two other controlling parameters that have to be considered in the material selection of CBSs, are (1) the water-entry value, $\psi_{\mathrm{w}}$ of coarse-grained layer (preferably $<1 \mathrm{kPa}$ ) and (2) the coefficient of saturated permeability, $\mathrm{k}_{\mathrm{s}}$ of the fine-grained layer (preferably $>10^{-5} \mathrm{~m} / \mathrm{s}$ ).

Tension crack in soil can cause leakage that had adverse effects to the barrier system, thus non-cohesive soil such as sand is commonly used for the construction of CBS. In sandy materials, water can drain very fast due to its low air entry value and low residual suction ([10], [11]).

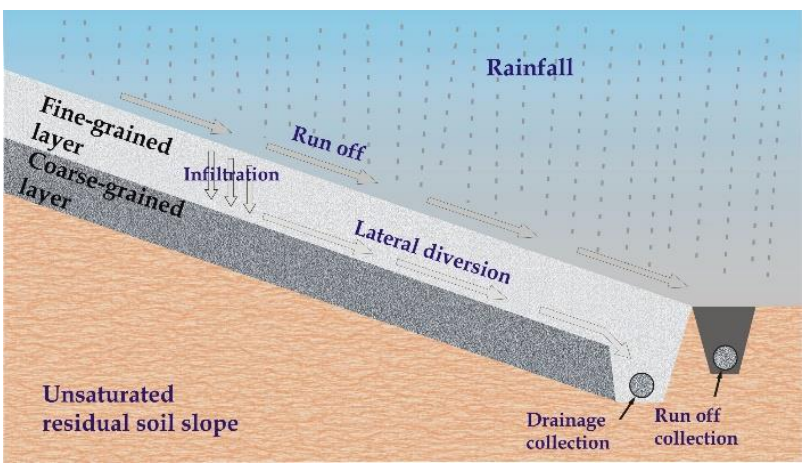

Fig. 1. Schematic diagram of capillary barrier system.

\footnotetext{
* Corresponding author: alfrendo.satyanaga@nu.edu.kz
} 


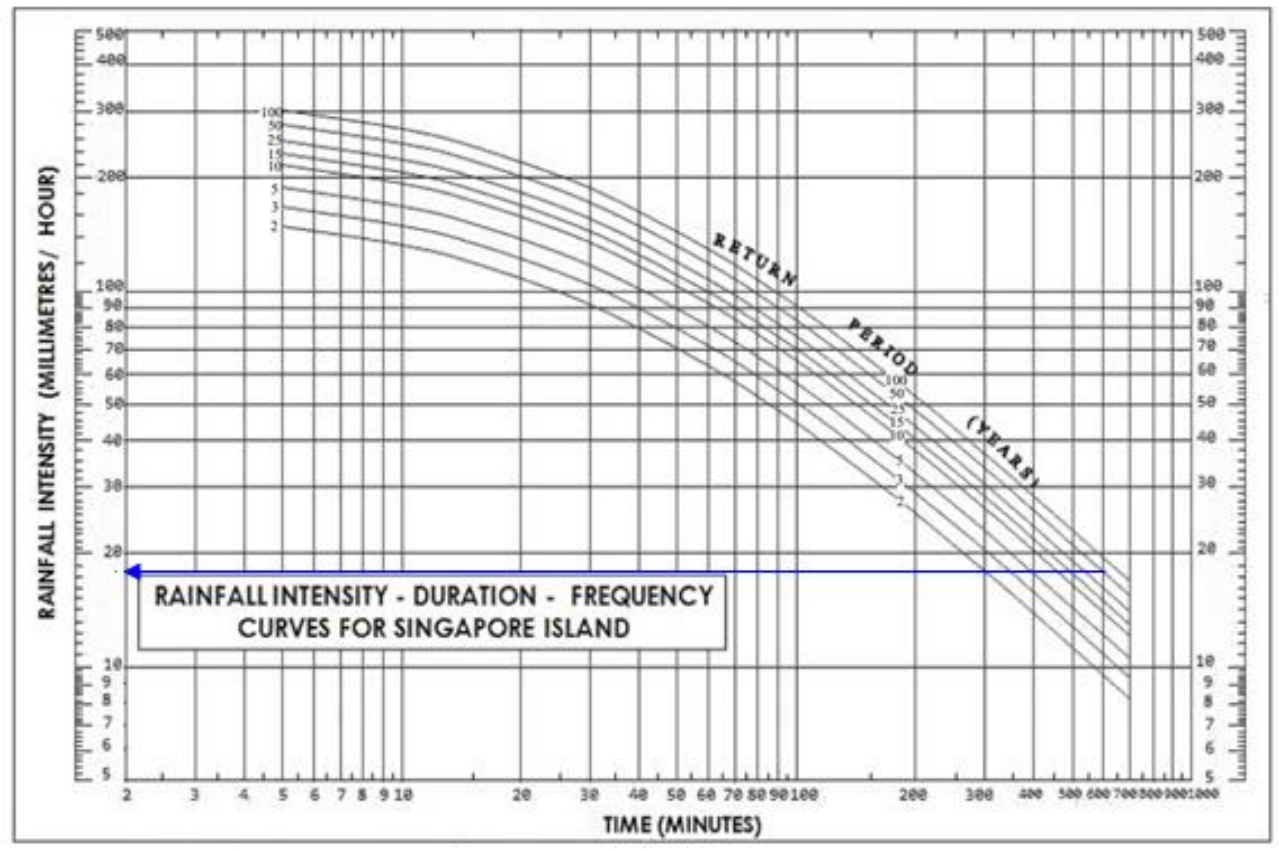

Fig. 2. Selection of rainfall condition from IDF curve [14].

As natural sand needs to be imported in Singapore, alternative material is needed to replace the natural sand in CBS due to its cost and limitation of resources. Recycled concrete aggregate (RCA) from construction and demolition waste, but mainly from crushed concrete of demolition waste is encouraged to be used in new construction work in Singapore. Rahardjo et al. (2020) [12] indicated that recycled construction material such as RCA could have similar performance as the natural sand in the capillary barrier.

In this study, the surface material of CBS was vegetated to provide greenery into the surrounding environment and for aesthetic purposes. An approved soil mixture (ASM) which is a mixture of organic soil and sandy material was used as the additional layer placed on top of the CBS for plant growth. In general, the CBS was constructed using three layers of soil with ASM as material as the top most layer, followed by fine RCA as fine-grained material and coarse RCA as coarse-grained material.

The objective of this paper is to describe the construction and performance of the CBS as a sustainable slope cover which was constructed surrounding basement carpark of HDB flats in Matilda, Singapore. The scope of works includes the installation of comprehensive instruments to provide real-time monitoring of rainwater infiltration into the slope and numerical analyses to assess the performance of CBS as a sustainable slope protection against rainfall-induced slope failure.

\section{Design of capillary barrier system}

The slope consists of residual soil from Old Alluvium in Matilda. It was located surrounding basement carpark of residential buildings in Singapore. In order to minimize the usage of electricity, the slope was designed with a gentle angle to provide sufficient sunlight into the carpark. The slope had a height of $3.5 \mathrm{~m}$ and a slope angle of $25^{\circ}$. Prior to the construction of CBS, numerical analyses were conducted to determine the optimum thickness of the CBS.

The CBS was designed with a thickness of $20 \mathrm{~cm}$ for the ASM, $30 \mathrm{~cm}$ for the fine-grained layer and $20 \mathrm{~cm}$ for the coarse-grained layer. Two-dimensional seepage analyses were carried out using the finite element software SEEP/W ([13]). During construction of the basement carpark, there is always one-meter overexcavation. In this case, there will be one-meter thick layer of backfill soil underlying CBS. The intensityduration-frequency (IDF) curve was used for the determination of flux boundary condition. A rainfall intensity of $18 \mathrm{~mm} /$ hour was determined from the curve corresponding to ten hours duration and return period of 50 years, as illustrated in Figure 2.

The numerical model and the boundary conditions were presented in Figure 3. Samples were taken from the site for SWCC measurements and the measured SWCCs of these soil samples were illustrated in Figure 4a. The statistical method as illustrated in Zhai et al. (2017 [15], 2018 [16]) equation was used for the estimation of the permeability functions shown in Figure $4 \mathrm{~b}$. Groundwater table was located at $1.5 \mathrm{~m}$ below the ground surface near the toe. Eight measurement points (as illustrated in Figure 3) were selected to assess the performance of CBS in minimizing the rainwater into the soil below the CBS.

Zhai et al. (2017) [17] and Tami et al. (2004) [18] suggested that the hysteretic behavior of hydraulic properties of soil needs to be accounted for in the numerical modeling of unsaturated flow system to provide realistic results. Therefore, both wetting SWCC and wetting permeability functions (as illustrated in Figure 4) were used for the seepage analysis. The results from the numerical analyses are illustrated in Figure 5.

\footnotetext{
* Corresponding author: alfrendo.satyanaga@nu.edu.kz
} 


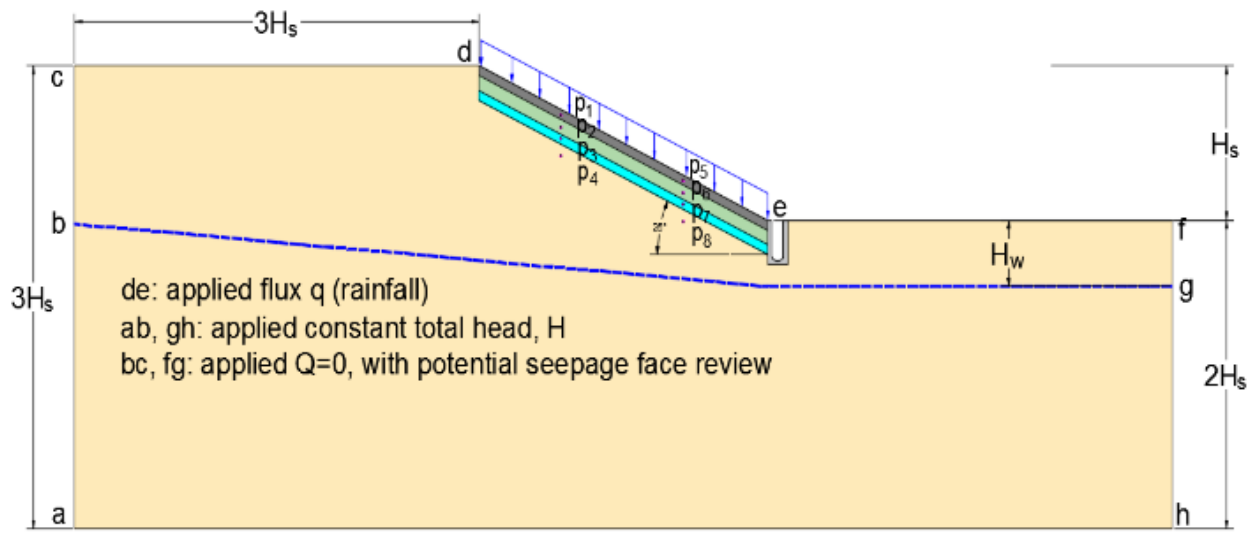

Fig. 3. Numerical model of capillary barrier system.

As illustrated in Figure 5, during the rainfall period (first 10 hours), a significant decrease in suction, which represents the occurrence of infiltration, is only observed in the ASM and fine RCA layers while an insignificant decrease is observed in the coarse RCA layers and no change in suction is observed in the backfill soil layer. The results from seepage analysis indicate that the CBS system has good performance in storing rainwater for plant growth and acting as a barrier to rainwater infiltration into the underlying soil layer.
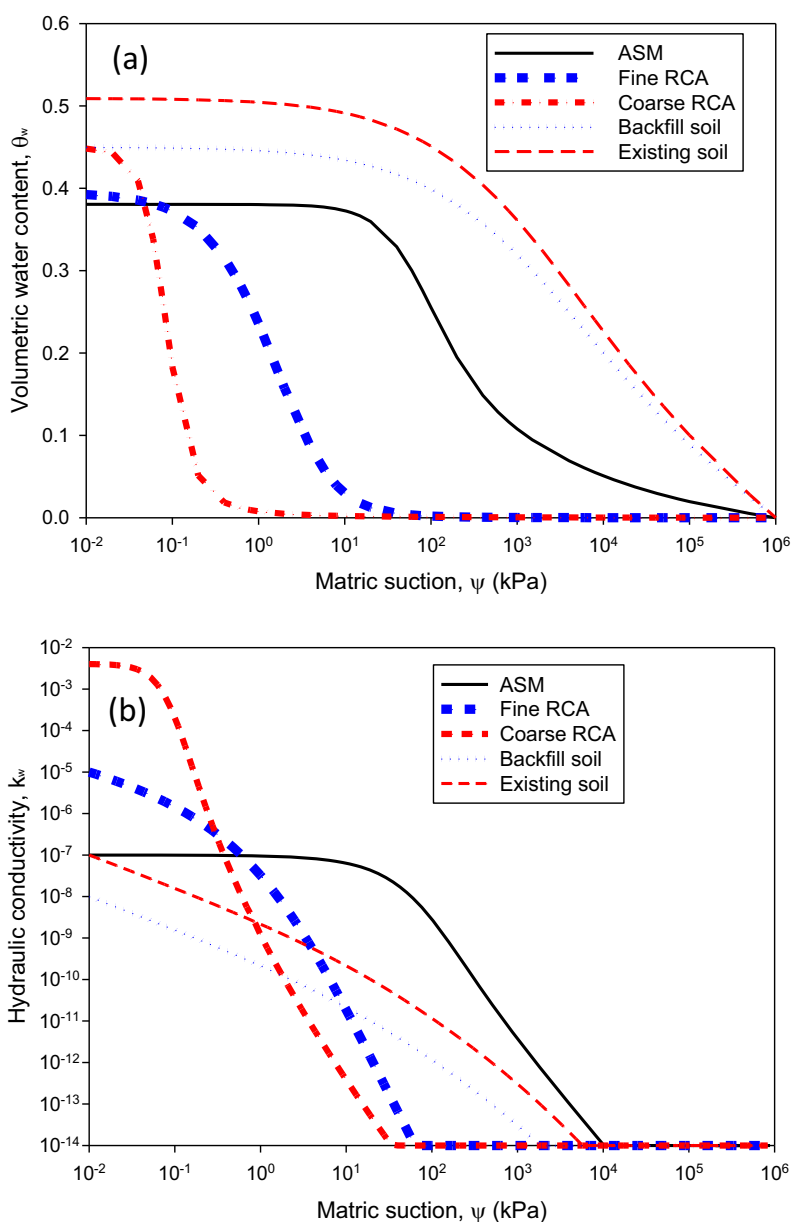

Fig. 4. Soil properties: (a) Soil-water characteristic curve (SWCC)s and (b) permeability functions of materials used in the numerical analyses of CBS slope.

\section{Construction of capillary barrier system}

The grain-size distribution (GSD) of materials used in CBS must be checked against the requirement (i.e., upper bound and lower bound of GSD) in the specification (HDB, 2016) [19] as presented in Figure 6 before they were placed on site. The selection of ASM must follow the specification as specified in Table 1 to ensure the livability of the plant.

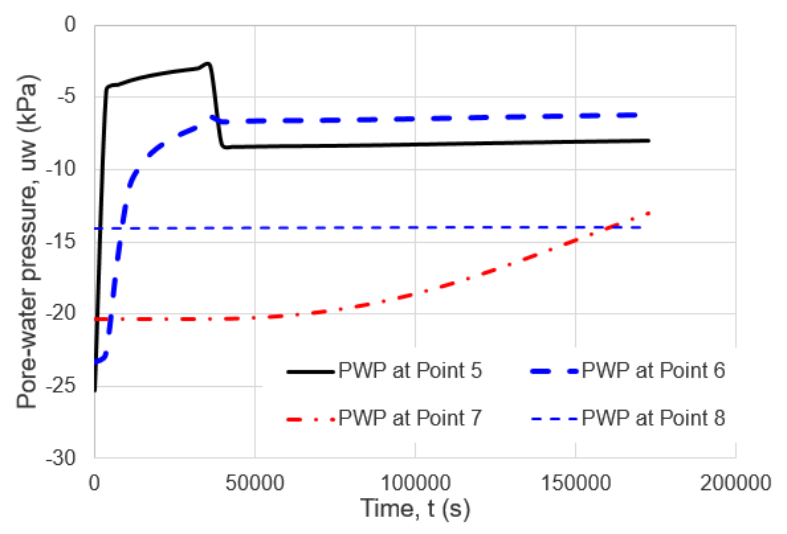

Fig. 5. Computed pore-water pressures at four points near crest of slope with respect to time.

Table 1. Specifications for ASM.

\begin{tabular}{|c|c|c|}
\hline S/No. & Parameters & Required Range/Value \\
\hline 1 & $\mathrm{pH}$ & 5.5 to 7.8 \\
\hline 2 & $\begin{array}{c}\text { Electrical } \\
\text { Conductivity }\end{array}$ & $\begin{array}{c}\text { Not exceeding } 1500 \mathrm{micron} / \mathrm{cm} \\
(1500 \mathrm{mS} / \mathrm{cm})\end{array}$ \\
\hline 3 & Components & $\begin{array}{c}\text { Particle size: between } 0.05 \text { to } \\
\text { 2mm. Proportion: from } 20 \% \text { to } \\
75 \% \text {. }\end{array}$ \\
\hline i) & Sand & $\begin{array}{c}\text { Particle size: between } 0.002 \text { to } \\
\text { 0.05mm. Proportion: from } 5 \% \\
\text { to } 60 \% .\end{array}$ \\
\hline ii) & Silt & $\begin{array}{c}\text { Particle size: less than } \\
0.002 \mathrm{~mm} \text {. Proportion: from } 5 \% \\
\text { to 30\%. }\end{array}$ \\
\hline iii) & Clay & \\
\hline
\end{tabular}

\footnotetext{
* Corresponding author: alfrendo.satyanaga@nu.edu.kz
} 


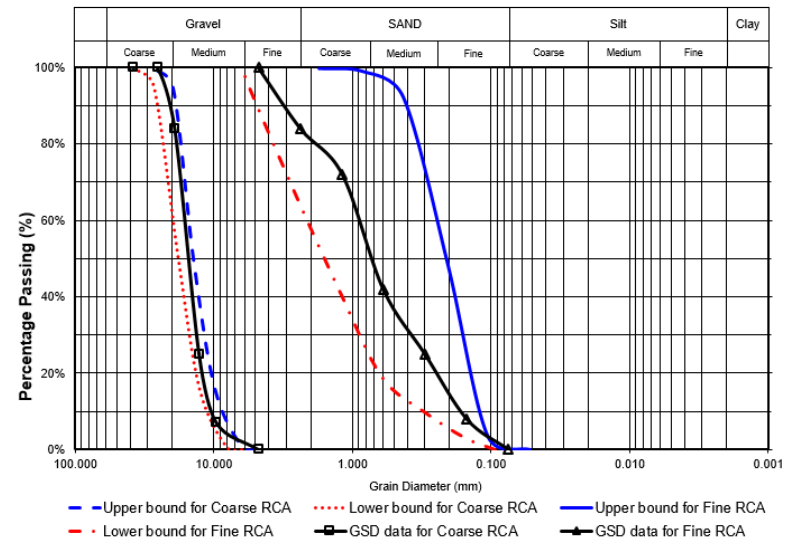

Fig. 6. Grain-size distribution of Fine and Coarse RCAs.

The construction of the CBS was started by trimming the slope into the designated slope angle of $25^{\circ}$. Then, it was followed by the installation of the surface drainage. The subsoils drainage pipe consisted of a PVC pipe perforated in the upper-half diameter, wrapped by the geotextile, placed at the toe of CBS for each layer of soil behind the surface drainage. Pipe guides were installed afterward to indicate the location and prepare the hole for tensiometers that would be installed after the entire CBS was built. The ASM soil, fine RCA and coarse RCA were placed within the geocell with a thickness of $20 \mathrm{~cm}, 30$ $\mathrm{cm}$ and $20 \mathrm{~cm}$, respectively, parallel to the slope surface. The geocell was similar to the one used by Rahardjo et al. (2016) and it was secured to the residual soil by steel Jpins of $40 \mathrm{~cm}$ long, penetrating to $20 \mathrm{~cm}$ depth into the ground. Manual compaction was carried out on the fine and coarse RCA to achieve the desired density.

During installation of the CBS (including three layers such as coarse RCA, fine RCA, and ASM soil), a layer of geotextile was laid on top of the coarse RCA as a separator between the coarse and fine RCA. A second layer of geocells was then laid above the geotextile and secured by steel J-pins of $80 \mathrm{~cm}$ long, penetrating to a depth of $20 \mathrm{~cm}$ into the ground. Fine RCA was then used to fill up the geocells to form the fine-grained layer. Another layer of geotextile was laid on top of the fine RCA as a separator between the fine RCA and ASM. The ASM was placed on top of the geotextile. Finally, vegetations were planted in the ASM layer. The comparisons between the measured grain size distribution (GSD) data and the specified range (i.e., upper bound and lower bound) in the specification from HDB (2016) are illustrated in Figure 6. The construction of CBS is presented in Figure $7 \mathrm{a}$ while the completed CBS slope is illustrated in Figure $7 \mathrm{~b}$.

\section{Field monitoring and numerical simulation}

In order to assess the performance of CBS in minimizing rainwater infiltration into the slope, a total of 12 jet-filled tensiometers [20] were installed in the different layers of soil (as illustrated in Figure 8). In order to check the reading from the pressure transducer, an additional bourdon gauge was attached to each tensiometer as illustrated in Figure 9. The readings of instruments on site were automatically collected by datalogger and stored in a server.

On the other hand, the numerical models for the seepage analyses were created using two commercial software Seep/W and SVFlux (version GE) in order to assess the response of field instruments to the rainfall. The collected rainfall data (from 1-Jan 2017 to 30-Jun 2017) from the weather station were used as the flux boundary condition for the seepage analyses. To avoid cumulative numerical error from the long-term iteration, a short simulation period such as one week was adopted for the seepage analysis. The half-year monitoring period was divided into twenty-six weeks and a total of 26 models were created. The readings from the tensiometers collected at the beginning of each week were assigned to the model and set as the initial condition for the seepage analysis. The final numerical results from the seepage analyses using both Seep/W and SVFlux (version GE) for 26 weeks are illustrated in Figures 10 to 15 . As the reference, the rainfall data from 1-Jan 2017 to 30-Jun 2017 are also plotted in Figures 10 to 15.
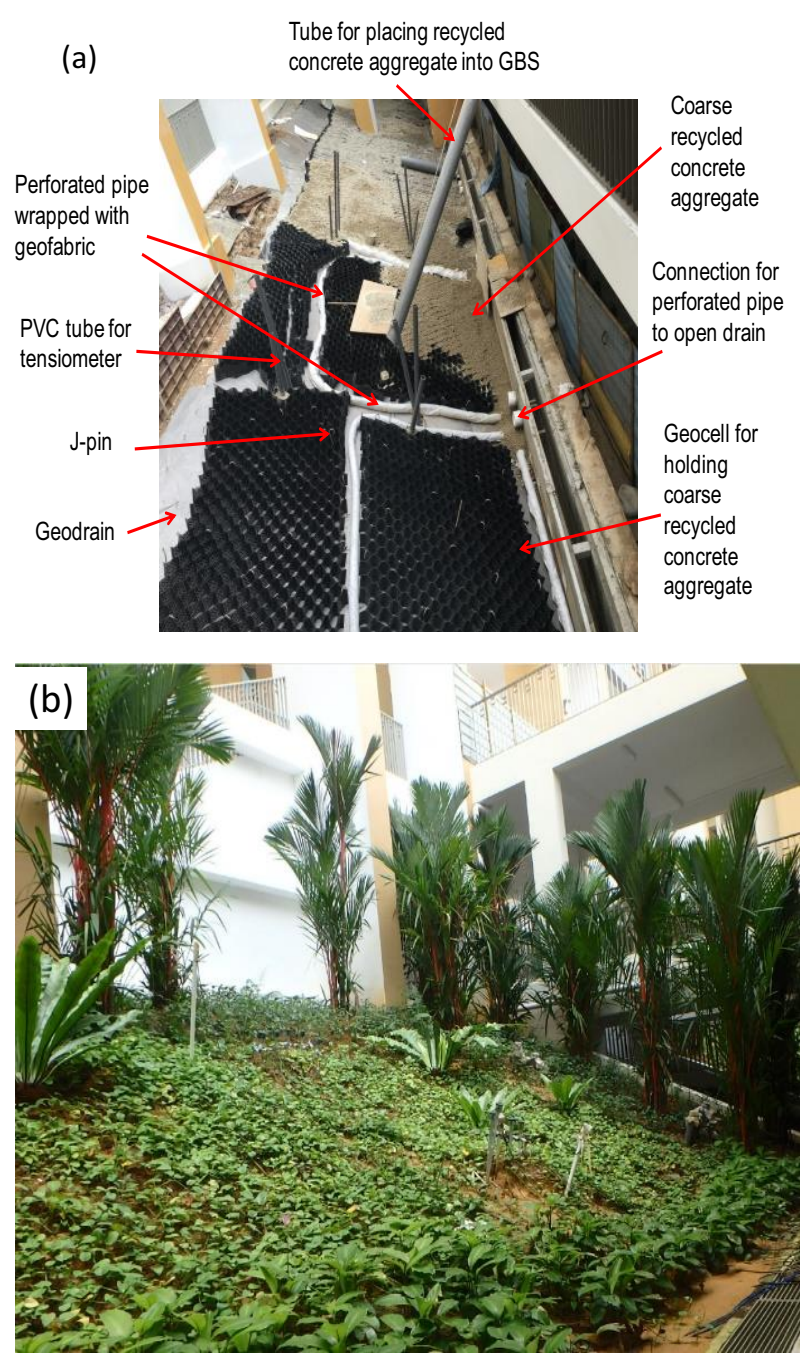

Fig. 7. (a) During and (b) after construction of CBS slope at Matilda. 


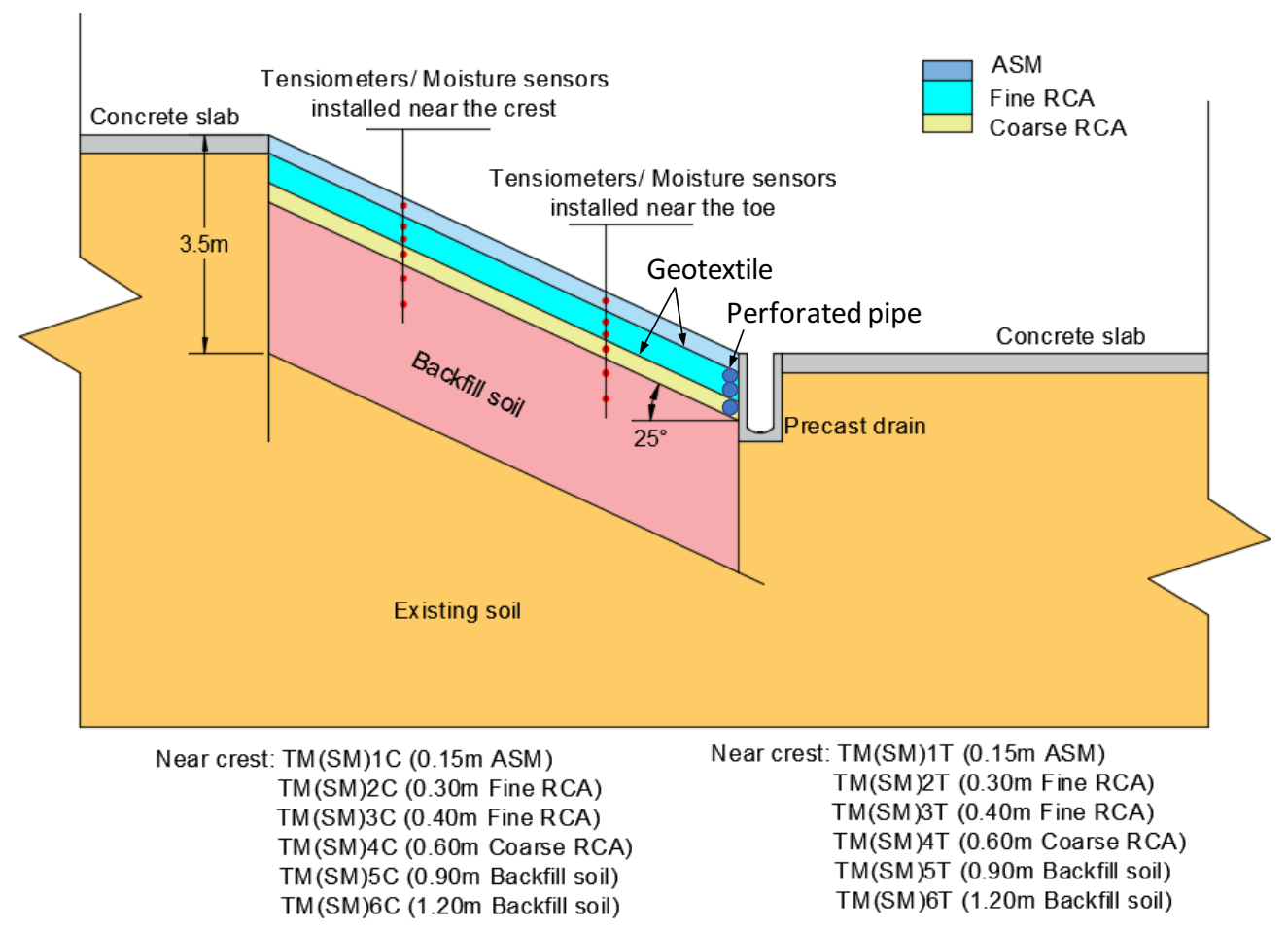

Fig. 8. Schematic diagram of capillary barrier system at Matilda.

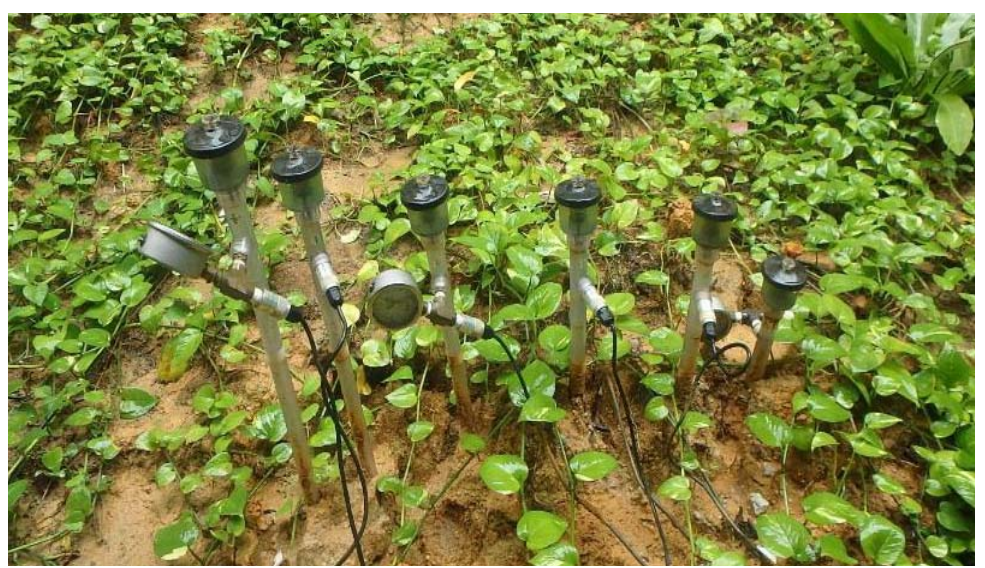

Fig. 9. Tensiometer installed on site.

It is observed that the suction in the ASM decreased much faster than that in the fine RCA during rainfall. The suction in the coarse RCA remained constant during the rainfall. It is also observed that ASM could remain in a relative low suction state during the dry period (such as Feb 2017) which can provide sufficient water for the plant growth. During the dry period, such as Feb-2017, there was limited rainfall recorded, the suction in ASM did not increase drastically, which means that the ASM can store the rainwater as the water supply for plant growth. The stored water could not infiltrate into the underlying soil due to the barrier effect provided by fine and coarse RCA layers.

As illustrated in Figures 10-15, the numerical results from the commercial software such as Seep/W and SVFlux (version GE) agree with each other. In addition, Figures 10 to 15 also indicate that the results from the seepage analyses (either using Seep/W or SVFlux (version GE)) agree with the field measurement data. Good agreements between the numerical results and the field measurements demonstrate that the performance of CBS can be assessed using the numerical method. Both field measurement data and numerical results show that the suction in the coarse RCA layer remained constant (with low fluctuation), indicating that there was no rainwater infiltrating into the underlying soil. Both measurement data and simulation results showed that the low suction value was observed in the ASM layer during dry season (no rainfall period), indicating the presence of water was within the ASM layer. On the other word, the rainwater infiltrated into ASM layer during wet season could be stored in the ASM layer during dry season. The stored rainwater can be used by vegetation planted on the surface of CBS. 

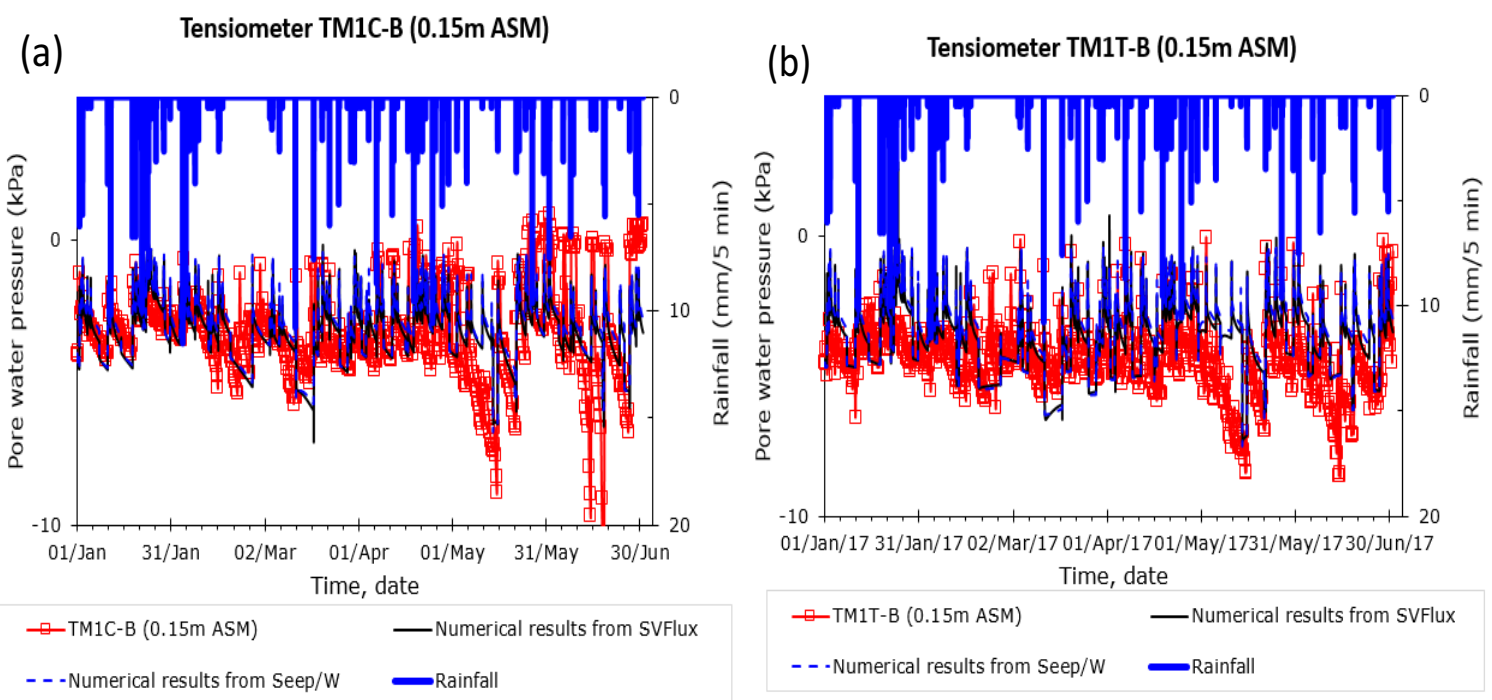

Fig. 10. Comparison results for Tensiometer 1 in ASM at: (a) crest and (b) toe.
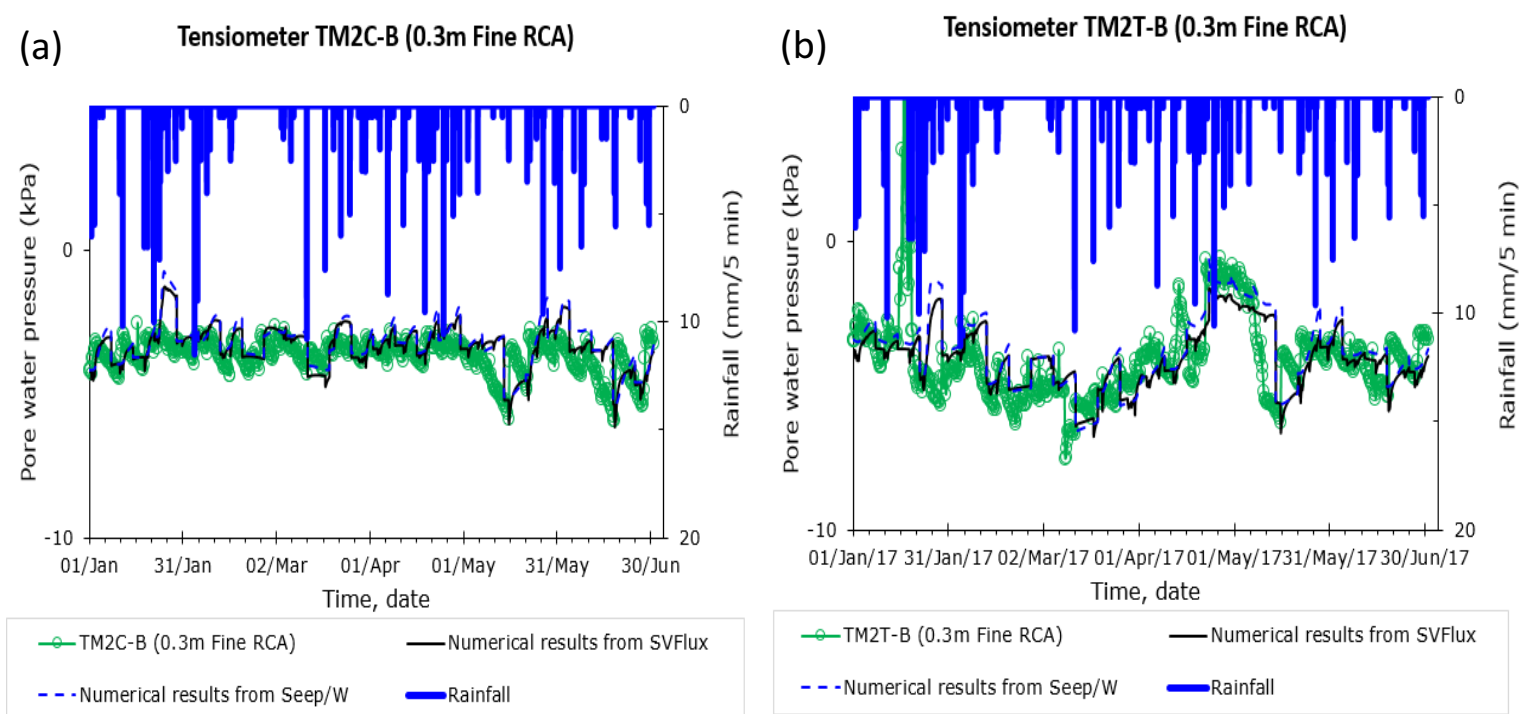

Fig. 11. Comparison results for Tensiometer 2 in fine RCA at: (a) crest and (b) toe.
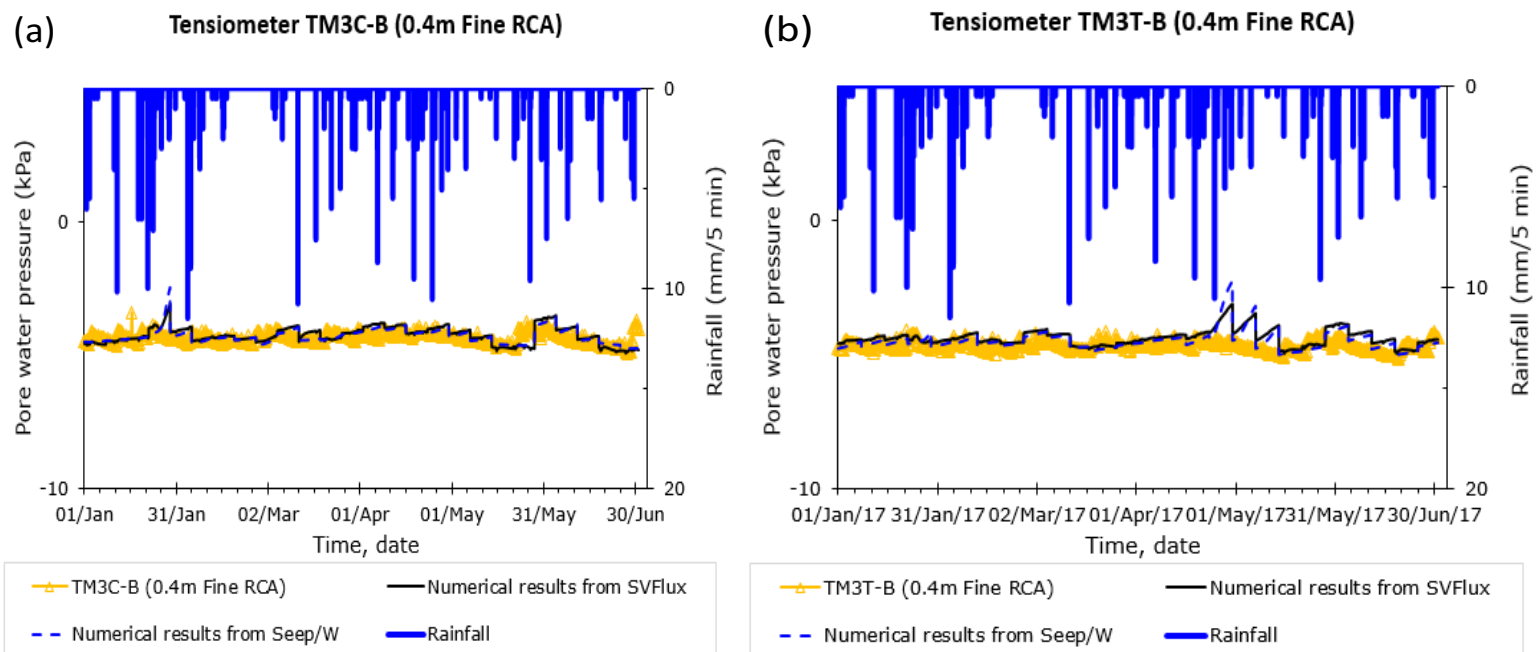

Fig. 12. Comparison results for Tensiometer 3 in fine RCA at: (a) crest and (b) toe.

\footnotetext{
* Corresponding author: alfrendo.satyanaga@nu.edu.kz
} 
(a) Tensiometer TM4C-B (0.6m Coarse RCA)

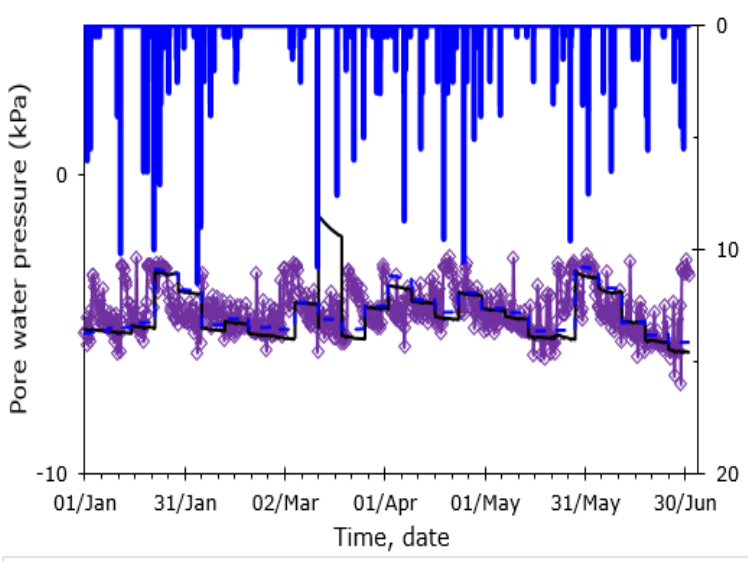

$\rightarrow$ TM4C-B $(0.6 \mathrm{~m}$ Coarse RCA $) \quad$ Numerical results from SVFlux

- - Numerical results from Seep/W _ Rainfall (b) Tensiometer TM4T-B (0.6m Coarse RCA)

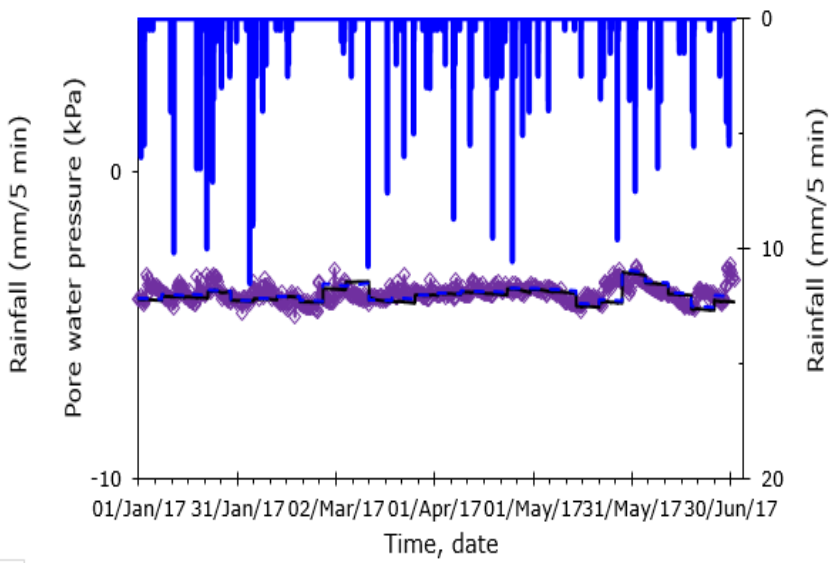

$\rightarrow$ TM4T-B (0.6m Coarse RCA) - Numerical results from SVFlux

- - Numerical results from Seep/W _ Rainfall

Fig. 13. Comparison results for Tensiometer 4 in coarse RCA at: (a) crest and (b) toe.

(a)

Tensiometer TM5C-B (0.9m Backfilling soil)

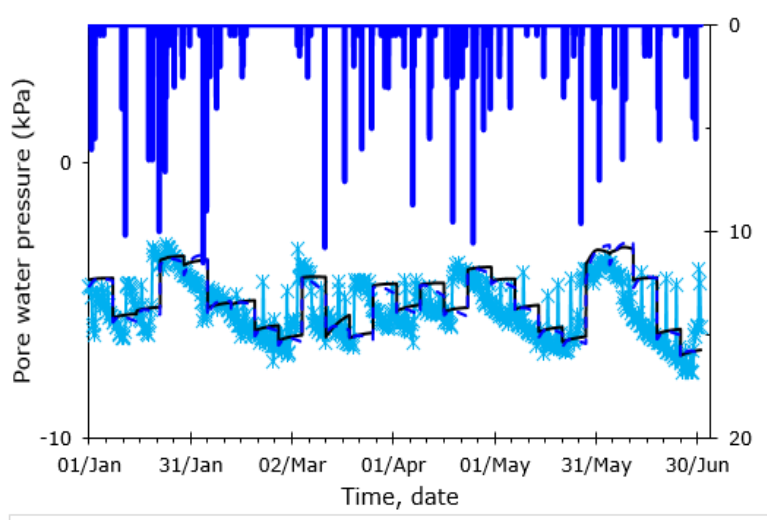

*-TM5C-B (0.9m backfilling soil) — Numerical results from SVFlux

- - Numerical results from Seep/W _Rainfall (b) Tensiometer TM5T-B (0.9m Backfilling soil)

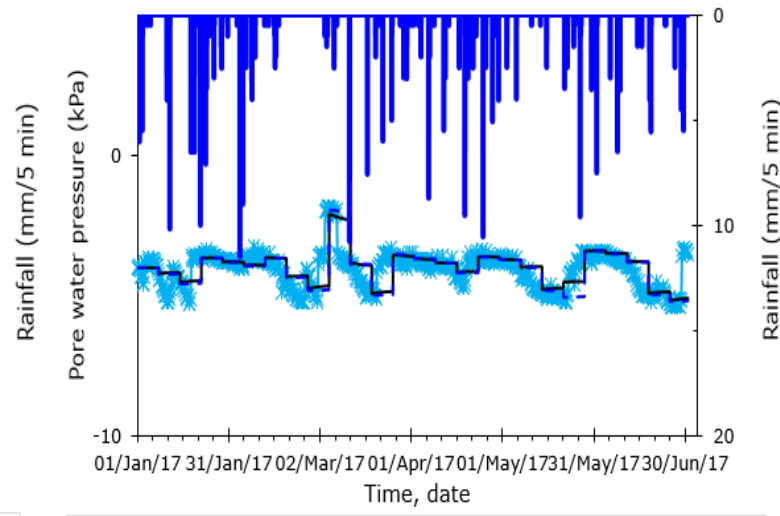

—-TM5T-B (0.9m Backfilling soil) — Numerical results from SVFlux

- - Numerical results from Seep/W —Rainfall

Fig. 14. Comparison results for Tensiometer 5 in backfilled soil at: (a) crest and (b) toe.

(a)

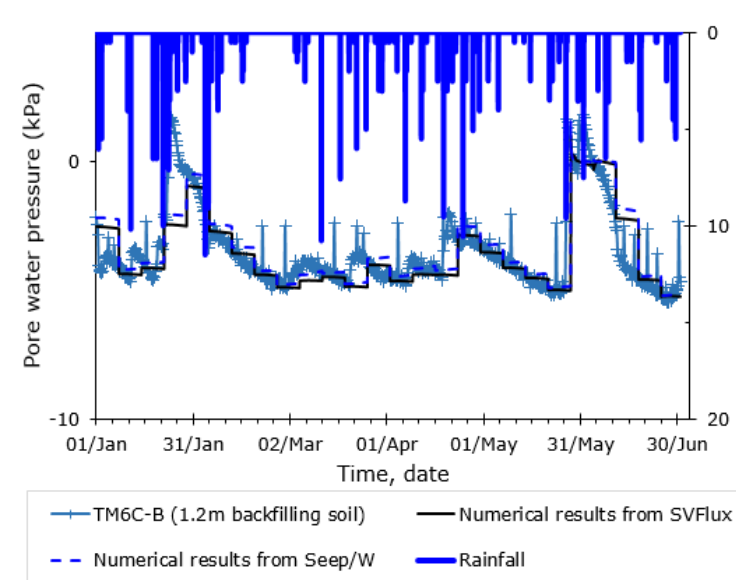

(b) Tensiometer TM6T-B (1.2m Backfilling soil)

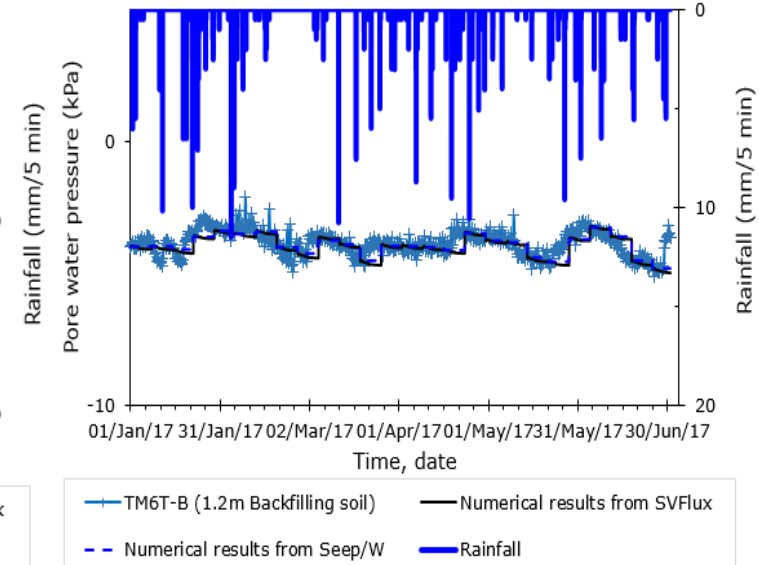

Fig. 15. Comparison results for Tensiometer 6 in backfilled soil at: (a) crest and (b) toe. 


\section{Conclusions and recommendations}

Capillary Barrier System (CBS) is a sustainable slope protection which consists of ASM, Fine RCA and Coarse RCA. A CBS was designed and constructed on the slopes surrounding a basement carpark in a public housing development at Matilda, Singapore. Both results from field instrumentation and numerical analyses indicate that the constructed CBS performed well under the studied rainfall conditions.

\section{Acknowledgements}

The authors gratefully acknowledge the support from Housing and development Board, Singapore and staffs in School of Civil and Environmental Engineering, Nazarbayev University during the data collections.

\section{References}

1. A. Satyanaga, H. Rahardjo, C.J. Hua. (2019). Numerical simulation of capillary barrier system under rainfall infiltration. ISSMGE Int. J. Geo. Case Histories. 5:1, 43-54. doi: 10.4417/IJGCH-05-01-04

2. H. Rahardjo, A. Satyanaga, F.R. Harnas, E.C. Leong. (2016). Use of dual capillary barrier as cover system for a sanitary landfill in Singapore. Indian Geo. J. 46:3, 228-238. doi: 10.1007/s40098-015-0173-3

3. H. Rahardjo, A. Satyanaga, F. R. Harnas, J-.Y. Wang, E.C. Leong. (2013). Capillary barrier system for landfill capping. Proc. Coupled Phenomena in Env. Geo. (CPEG), TC215 Symposium, 1 - 3 July 2013, Torino, Italy.

4. C.E. Morris \& J.C. Stormont. (1998). Evaluation of numerical simulations of capillary barrier field tests. G. \& G. Eng. 16, 201-213.

5. H. Rahardjo, A. Satyanaga, N. Gofar, E.C. Leong, J.H.L. Kew, C.L. Wang, J.L.H. Wong. (2019). Geobarrier system for protection against rainfallinduced slope failure. ISSMGE Int. J. Geo. Case Histories. 5:1, 26-42. doi: 10.4417/IJGCH-05-01-03

6. H. Rahardjo, N. Gofar, F. Harnas, A. Satyanaga. (2018). Effect of geobags on water flow through capillary barrier system. Geo. Eng. J. SEAGS \& AGSSEA . 49:4, 1-6.

7. H. Rahardjo, A. Satyanaga, E.C. Leong. (2012). Unsaturated soil mechanics for slope stabilization. Southeast Asian Geo. J. 43:1, 48-58.

8. H. Rahardjo, V.A. Santoso, E.C. Leong, Y.S. Ng, C.J. Hua. (2012). Performance of an instrumented slope covered by a capillary barrier system. ASCE J. Geo. and Geoenv. Eng. 138:4, 481 - 490. doi: 10.1061/(ASCE)GT.1943-5606.0000600
9. H. Rahardjo, V.A. Santoso, E.C. Leong, Y.S. Ng, C.P.H. Tam, A. Satyanaga. (2013). Use of recycled crushed concrete and secudrain in capillary barriers for slope stabilization. Canadian Geotechnical J. 50: 1-12. doi: 10.1139/cgj-2012-0035

10. D.G. Fredlund \& H. Rahardjo. (1993). Soil mechanics for unsaturated soil. Wiley, New York.

11. D.G. Fredlund, H. Rahardjo \& M.D. Fredlund. (2012). Unsaturated soil mechanics in engineering practice. Wiley, New York

12. H. Rahardjo, Y. Kim, N. Gofar, A. Satyanaga. (2020). Analyses and design of steep slope with GeoBarrier System under heavy rainfall. Geotextiles and Geomembranes. 48:2, 157-169. doi: 10.1016/j.geotexmem.2019.11.010

13. H. Rahardjo, A. Satyanaga, E.C. Leong, Y.S. Ng, M.D. Foo, C.L. Wang. (2007). Slope failures in Singapore due to rainfall. Proc. 10th ANZ Conf. on Geomechanics "Common Ground". Brisbane, Australia, 21-24 October, 2, 704 - 709.

14. H. Rahardjo, A. Satyanaga, E.C. Leong. (2016). Effects of rainfall characteristics on the stability of tropical residual soil slope. Proc. E-UNSAT 2016. 15004. 1-6. doi: 10.1051/e3sconf/20160915004

15. Q. Zhai, H. Rahardjo, A. Satyanaga, Priono. (2017). Effect of bimodal soil-water characteristic curve on the estimation of permeability function. Eng. Geology. 230, 142-151. doi: 10.1016/j.enggeo.2017.09.025

16. Q. Zhai, H. Rahardjo, A. Satyanaga. (2018). A poresize distribution function based method for estimation of hydraulic properties of sandy soils. Eng. Geology. 246, 288-292. doi: 10.1016/j.enggeo.2018.09.031

17. Q. Zhai, H. Rahardjo, A. Satyanaga. (2017). Uncertainty in the estimation of hysteresis of soilwater characteristic curve. Env. Geo. doi: 10.1680/jenge. 17.00008

18. D. Tami, H. Rahardjo, E.C. Leong, D.G. Fredlund. (2004). Design and laboratory verification of a physical model of sloping capillary barrier. Canadian Geotechnical J. 41, 814- 830. doi: 10.1139/t04-036

19. Housing \& Development Board (HDB). (2016). Construction of geobarrier system. Technical specification.

20. H. Rahardjo, A. Satyanaga, E.C. Leong, J.-Y. Wang. (2014). Comprehensive instrumentation for real time monitoring of flux boundary conditions in slope. Procedia Earth and Planetary Science. 9, 23-43. doi: 10.1016/j.proeps.2014.06.015

\footnotetext{
* Corresponding author: alfrendo.satyanaga@nu.edu.kz
} 